\title{
Artigos acadêmicos da área de história: heterovocalidade, diversidade composicional e estilística
}

Dóris de Arruda C. da Cunha*

Resumo: Este artigo apresenta os resultados de um estudo sobre o modo como artigos acadêmicos da área de História se constituem e se fundamentam no discurso do outro. Parte da reflexão epistemológica de Bakhtin (2003), mas se apoia em outros autores do campo da abordagem dialógica, da filosofia da ciência e da circulação do discurso. A análise do corpus mostra a heterovocalidade inerente ao gênero; a bivocalidade específica do discurso acadêmico; a diversidade composicional; e, consequentemente, a diversidade estilística - os diferentes modos de dizer e de representar a alteridade "desenham" um estilo do autor.

Palavras-chave: Artigo acadêmico. Área de História. Heterovocalidade. Diversidade composicional e estilística.

\begin{abstract}
This article presents the results from a study examining how academic articles published in the field of history are constituted and based on the discourse of the other. It is grounded in Bakhtin's (2003) epistemological reflection, but it is also based on other authors whose fields range from the dialogic, the philosophy of science and the circulation of discourse approaches. The analysis demonstrates the heterovocality inherent to the genre; the bivocality that is specific to the academic discourse; the compositional heterogeneity; and, consequently, the stylistic heterogeneity - the different modes of saying and representing alterity "compose" a style of the author.
\end{abstract}

Keywords: Academic article. History Field. Heterovocality. Compositional and stylistic diversity.

Résumé: Cet article présente les résultats d'une étude sur le mode comme les articles académiques du domaine de l'histoire se constituent à partir du discours de l'autre. Il part de la réflexion épistémologique de Bakhtin (2003), mais s'appuie sur d'autres auteurs dans le domaine de l'approche dialogique, de la philosophie des sciences et de la circulation du discours. L'analyse du corpus montre et l'hétérovocalité inhérente au genre ; la bivocalité spécifique du discours académique ; la diversité compositionnelle; et, par conséquent, stylistiques - les différentes manières de dire et de représenter l'altérité «dessinent» un style de l'auteur.

Mots clés: Article académique. Domaine de l'Histoire; Hétérovocalité; Diversité compositionnelle et stylistique

\footnotetext{
* Professora Titular da Universidade Federal de Pernambuco (aposentada) e professora do Programa de Pós-graduação em Ciências da Linguagem da Universidade Católica de Pernambuco. Bolsista de produtividade do CNPq. http://orcid.org/oooo-0001-5349-2887
}

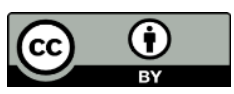

Este artigo está licenciado sob forma de uma licença Creative Commons Atribuição 4.0 Internacional, que permite uso irrestrito, distribuição e reprodução em qualquer meio, desde que a publicação original seja corretamente citada. 
Este artigo resulta da investigação sobre o discurso do outro ${ }^{1}$ em textos da área de ciências humanas ${ }^{2}$. A pesquisa partiu da reflexão epistemológica de Bakhtin (2003, p. 311), sobre "a especificidade do pensamento das ciências humanas, voltado para pensamentos, sentidos e significados dos outros etc., realizados e dados ao pesquisador apenas sob a forma de texto" (BAKHTIN, 2003, p. 308). O trabalho se apoia ainda em autores do campo da abordagem dialógica, da filosofia da ciência e da circulação dos discursos 3 . O foco da análise é o modo como os textos dessa área se constituem e se fundamentam no discurso do outro, como o introduzem e o assimilam, entre outras atividades. O corpus também orientou os caminhos a percorrer na análise. Por essas razões, apresento inicialmente os procedimentos metodológicos, especialmente a escolha do corpus, seguidos do enquadre teórico e das análises realizadas.

\section{Questões metodológicas}

Em um estudo de teses da área de Linguística (CUNHA, 2019), observei uma grande diversidade de modos de relação ao discurso do outro: marcado, mostrado, aludido, assimilado, misturado com o discurso do enunciador. A comparação de fragmentos das teses revelou modos preferenciais de interação com o discurso do outro

\footnotetext{
${ }^{1}$ Há uma grande variação terminológica para se referir ao discurso do outro, fruto de numerosas pesquisas, referente ao dizer sobre o dizer e no dizer. Uso indistintamente discurso do outro, discurso alheio, vozes, representação do discurso. O interesse está na questão da retomada de um texto pelo pesquisador, um acontecimento que cria o novo e se dá na forma de diálogo "do texto (objeto de estudo e reflexão) e do contexto emoldurador a ser criado (que interroga, faz objeções, etc.) no qual se realiza o pensamento cognitivo e valorativo do cientista" (BAKHTIN, 2003, p. 311).

${ }^{2}$ Esse artigo foi desenvolvido durante estágio de pós-doutorado, supervisionado pelo Prof. Carlos Alberto Faraco, que atua no Programa de Pós-graduação em Letras da UFPR. A proposta apresentada ao Programa de Pós-graduação da UFPR é um recorte do projeto de pesquisa, Discurso do outro, ponto de vista e interpretação nas ciências humanas, financiado com Bolsa de produtividade do CNPq (processo 306526/2016-6).

${ }^{3}$ Há diferentes perspectivas de análises de ou do discurso. Refiro-me aqui, de forma sumária, aos estudos que buscam compreender o funcionamento da linguagem ou do discurso, e não a estrutura da língua.
} 
bem como o estilo de cada autor, considerando estilo não como um ornamento adicionado ao texto, mas na perspectiva de Bakhtin (2003) que o vincula ao gênero; e de François (2015), que o associa à compreensão ou à recepção, postulando que há modos de fazer, de dizer, de compreender que "desenham" um estilo.

Como há diversos gêneros e estilos na esfera acadêmica, o projeto previa investigar o "diálogo" com a palavra do outro em artigos acadêmicos, tendo em vista que “compreender é cotejar com outros textos e pensar num contexto novo" (BAKHTIN, 2003, p. 404).

Mas a opção por esse recorte não foi feita sem dificuldades. Em primeiro lugar, a perspectiva dialógica é qualitativa, sendo difícil analisar muitos textos porque é importante observar os movimentos discursivos de cada um deles. Além disso, o campo das ciências humanas é muito vasto e as variáveis são numerosas: áreas (história, arqueologia, sociologia, antropologia, ciência política, geografia); gêneros (livros, artigos, conferências); experiência acadêmica (pesquisadores sêniores e iniciantes). Decidi então estudar a produção da área de história, que pode fornecer uma reflexão empírica relevante sobre o tema da pesquisa, uma vez que o historiador trabalha majoritariamente com documentos escritos.

A escolha do gênero deve-se não só à relevância dos artigos na esfera de atividade científica, mas também ao fato de que poderia analisar um número maior de artigos do que de livros e de teses. Com relação ao perfil do pesquisador, optei por estudar a escrita acadêmica de pesquisadores sêniores, que são referência na área4

A partir dessas escolhas, selecionei artigos de historiadores classificados no mais alto nível pelo $\mathrm{CNPq}$ (nível $1 \mathrm{~A}$ e pesquisador emérito): (1) Ditadura, anistia e reconciliação; e (2) As revoluções russas e a emergência do socialismo autoritário, de Daniel Aarão Reis Filho, (professor titular e pesquisador 1A do $\mathrm{CNPq}$ ); (3) História do Brasil e revisões historiográficas, de Maria Helena Rolim Capelato, (professora titular e pesquisadora $1 \mathrm{~A}$ do $\mathrm{CNPq}$ ); (4) República, democracia e federalismo. Brasil, 1870-1891 José Murilo de Carvalho (professor emérito da Universidade Federal do Rio de Janeiro,

\footnotetext{
${ }^{4} \mathrm{~A}$ escolha dos historiadores, dentre vinte e três pesquisadores sêniores brasileiros (nível 1A do CNPq), foi decorrente do meu interesse pelo trabalho deles.
} 
pesquisador emérito do CNPq, membro da Academia Brasileira de Ciências e da Academia Brasileira de Letras).

\section{O enquadre teórico}

A pesquisa se fundamenta nos escritos de Bakhtin (2016; 2015; 2010; 2003; 1997) e dialoga com autores que discutem questões epistemológicas, filosóficas, enunciativas e discursivas (AUTHIER-REVUZ, 2020; 2015; 2004; FARACO, 2013; 2017; FRANÇOIS, 2015, 2014, 2009; GINGRAS 2013; LATOUR e FABRI, 1977; LOWY, 2000; STANGERS, 2006).

\subsection{O texto nas ciências humanas}

O ponto de partida da pesquisa foram as ideias de Bakhtin (2003) sobre a especificidade do texto nas ciências humanas: "um pensamento sobre pensamentos, vivências das vivências, palavras sobre palavras, textos sobre textos" (BAKHTIN, 2003, p. 308).

Nos seus escritos do campo da epistemologia, Bakhtin compara as ciências humanas com as ciências exatas (ciências matemáticas e naturais), considerando essas últimas

uma forma monológica de saber: o intelecto contempla uma coisa e emite um enunciado sobre ela. Aí só há um sujeito: o cognoscente (contemplador) e falante (enunciador). A ele só se contrapõe a coisa muda. Qualquer objeto do saber (incluindo o homem) pode ser percebido e conhecido como coisa (BAKHTIN, 2003, p. 400).

Nessas áreas de conhecimento, o aparato metodológico 
se orienta para o domínio do objeto reitificado, mudo que não se revela na palavra, e que não comunica nada a respeito de si mesmo. O conhecimento aqui não está ligado à recepção e à interpretação das palavras ou sinais do próprio objeto a ser conhecido (BAKHTIN, 2003, p. 150).

Isso não quer dizer que o cientista não lide com a palavra de outrem: no fazer do trabalho científico, ele não pode não dialogar com os predecessores, no processo de elaboração do trabalho, mas não em relaçao ao conteúdo da ciência, como ressalta Bakhtin (2003) e como mostram Latour e Fabri (1977) em um trabalho sobre A retórica da ciência. Os pesquisadores franceses fizeram uma análise minuciosa de um artigo da área de neuroendocrinologia, onde mostram que o traço mais marcante do texto é que ele é recheado de referências, remetendo a obras, majoritariamente externas ao texto. Os autores constatam que o referente é composto de um empilhamento de textos: o contexto no qual o artigo age, o infratexto no qual ele se apoia, a parte B sobre a qual se baseia a parte A. Não é o referente que se encontra no que precede o texto e lhe sucede, mas outros textos que ele cita e que o citam. Nas palavra dos autores, é como se sua objetividade viesse das correspondências estabelecidas, sobrepondo uma sobre as outras as diferentes camadas de texto.

Embora não tenha feito pesquisa empírica, mas reflexões dedicadas a questões epistemológicas, Bakhtin (2003) trouxe algumas ideias muito importantes sobre a produção do conhecimento, o texto e o fazer específico no campo das ciências humanas. Merece destaque a definição do objeto nesse campo: a interrelação entre dois “espíritos”, o que estuda e o que é estudado (BAKHTIN, 2003, p. 380), que, segundo o autor, era ignorada pelas ciências humanas.

A concepção de ciências humanas como ciências do texto que retoma e interpreta outros textos é, evidentemente, indissociável do encontro com a palavra do outro e da dialogismo constitutivo dos textos. Nesse campo do saber, é importante observar não só a onipresença, mas a interação incontornável com o discurso do outro, com meios de molduragem bastante variados: os dizeres alheios podem ser isolados em citações com fronteiras inequívocas e distância máxima colocada pelo enunciador, passando por formas e graus de alteridade, até se misturar com o discurso do enunciador. Esses dizeres alheios podem se revelar por meio do relato ou menção de atos de fala, que condensam 
o discurso de outrem, e por alusões, que dependem do conhecimento compartilhado para serem interpretadas como tal (CUNHA, 2019).

François (2014) afirma que, nas ciências humanas, temos uma relação de diálogo com os grandes autores. No caso de teses, por exemplo, os doutorandos retomam o que dizem os autores mais reconhecidos e depois se esforçam com os fatos que supostamente obedecem às teorias. Isso porque não existe uma teoria global que seria a boa teoria. Há, em determinados momentos e para determinados estudiosos, quadros teóricos que são considerados adequados aos seus objetos.

Ainda de acordo com o autor francês, as ciências naturais tentam eliminar a particularidade do ponto de vista do pesquisador, enquanto nas ciências humanas não se pode eliminar o estilo de visão específico do objeto, a natureza das questões de pesquisa e, mais ainda, os pressupostos e implícitos. Daí o caráter dialogal da pesquisa em ciências humanas.

Chama atenção, nas reflexões de Bakhtin sobre a construção de uma epistemologia das ciências humanas, o fato de o filósofo não definir as noções de ciência, ciências humanas, embora saiba-se que tanto ele como Volóchinov (2017) eram críticos ferrenhos do positivismo e do formalismo das primeiras décadas do século XX. É possível que seja porque os textos não foram finalizados pelo autor para publicação. Trata-se, entretanto, de uma discussão importante para se pensar sobre o texto nas ciências humanas.

François (2015) questiona a noção de ciência, usada com artigo definido no singular, tendo em vista que não há uma única concepção de ciência. A noção questionada é o mais das vezes associada à noção de verdade, da visão positivista (STANGERS, 2006)5 , e contestada pela visão pragmática de ciência e pela sociologia da ciência (GINGRAS, 2013). François (2015) situa as ciências humanas no âmbito do ponto de vista, uma vez que não há duas interpretações idênticas do mesmo objeto, que as pesquisas são situadas, inscritas numa história, num campo, marcadas pelas condições que influem sobre os objetos e pela independência dos pesquisadores. Para o autor, no campo das ciências humanas, há um saber acumulado, mas estamos no campo da

\footnotetext{
${ }^{5}$ Stangers (2006) opõe a visão positivista à visão pragmática de ciência.
} 
circulação de interpretações ou de comentários que outras interpretações e comentários podem retomar, criticar, modificar, reacentuar sem que haja razão para o processo ser interrompido.

A noção de ponto de vista determinando o objeto, como propôs Saussure, é defendida por teóricos das ciências sociais (WEBER, apud LÖWY, 20oo; LATOUR e FABRI, 1977). Esses dois últimos afirmam que ter um ponto de vista é a condição do trabalho científico. A concepção de ponto de vista que adoto será rapidamente discutida a seguir, mas antes é necessário indicar algumas noções subjacentes à análise.

\subsection{Língua e linguagem}

Este trabalho se insere numa perspectiva linguageira ou discursiva, diferente daquela estritamente linguística que aborda a língua por ela mesma, examinando as unidades reiteráveis e submetidas a regras de combinação.

Assim concebida, a língua é uma abstração, enquanto a linguagem concreta é de natureza variável em função do interlocutor, da situação, do contexto mais amplo, dos modos de recepção. A linguagem é o lugar do heterogêneo, produz sentidos na relação com os entornos, com outras semiologias e na sua circulação. A diferença entre as abordagens discursivas e linguística stricto sensu está no fato de as primeiras estudarem os modos variados de funcionamento e de circulação da linguagem, incluindo o nãoverbal com toda a sua complexidade e de não se limitar às regularidades da língua.

Analisar a linguagem concreta traz ainda a questão de como as palavras do outro são apreendidas. Respondemos a qualquer texto como a qualquer evento por formas de acordo e desacordo, distanciamentos, retificações, questionamentos sobre a veracidade ou falsidade do dito, e assim por diante. Além disso, lidar com a linguagem significa lidar com a experiência própria de cada um, com afetos e valores na produção e interpretação dos sentidos.

Essa opção também leva a evidenciar que o estudo da linguagem não se enquadra no modelo da linguística descritiva, mas situa-se no domínio da interpretação, ou da 
compreensão responsiva ativa, noção utilizada por Bakhtin (2003) e por Volóchinov (2017).

Um outro aspecto importante nessa visão de linguagem é seu caráter dialógico. Isso significa que o enunciador não é a única fonte do enunciado nem do sentido, visto que toda enunciação por mais significativa e completa que seja é apenas "um elo na cadeia da comunicação discursiva" (BAKHTIN, 2003, p. 229). Compreendido frequentemente como presença do outro em todas as produções verbais, seja por meio do já-dito, seja do por vir, das possíveis objeções e questionamentos do interlocutor, o dialogismo comporta também outras dimensões porque está ligado à condição humana e à heterogeneidade fundamental do sujeito.

A noção de dialogismo remete, portanto, à heterogeneidade das vozes, às formas de alteridade no enunciado, objeto de estudo de numerosos trabalhos há algum tempo, sendo desnecessário apresentar as categorizações de Volóchinov (2017) das formas de discurso reportado a partir do texto literário, de Bakhtin no estudo do romance (2016) e na obra de Dostoiévski (1997) bem como de Authier-Revuz (2020; 2015) e do autor deste artigo (CUNHA 2011; 2008; 1992). Vale salientar que os dois últimos abordam a questão do discurso reportado, renomeado representação do discurso outro pela linguista francesa, em muitos trabalhos, não cabendo citar todos aqui.

\section{3 "Sujeito" e ponto de vista}

A concepção bakhtiniana de "sujeito", singular, único e inacabado, que se constitui na relação com o outro (BAKHTIN, 2010; 2003) é adotada nessa pesquisa. Bakhtin (2010) articula a posição singular de cada um ao espaço, ao tempo e ao ato carregado de tons emotivos-volitivos e de valores. Daí a heterogeneidade constitutiva do "sujeito" e a não coincidência de nossos pontos de vista (FRANÇOIS, 2015).

Essa noção pode ser aproximada da de posicionamento axiológico (BAKHTIN, 2015; 2003). É do lugar único ocupado por cada "sujeito" histórico que ele percebe e apreende alguns aspectos da "realidade" múltipla e se posiciona. Oriundo de uma 
metáfora visual, o ponto de vista está ligado ao fato de que por um lado há uma realidade comum e por outro lado a realidade é dada de diversas formas. "Ponto de vista" pode ser definido como modo de perceber, de interpretar e tomar posição, de se relacionar com o mundo, com o outro e consigo mesmo "enquanto" (“en tant que”, FRANÇOIS, 2015), sendo, portanto, necessariamente contingente. O autor postula que não há "objetividade absoluta", que adotamos um ponto de vista, nos orientamos em relação ao discurso e dialogamos com ele, de forma mais ou menos justificada, argumentada, eventualmente demonstrada. Ele acrescenta que a questão do ponto de vista não pode ser separada da questão da linguagem uma vez que tratamos de pontos de vista ditos, procurando dizer algo que não sabemos como será lido.

\subsection{Gênero}

Em trabalhos anteriores, constatamos a interrelaçao entre formas e graus de alteridade, gênero e ponto de vista do enunciador (CUNHA, 2012).

O gênero discursivo é relativamente estável, em função da situação e do campo de atividade (BAKHTIN, 2003), refletindo essa situação de interação e a finalidade do campo em seu conteúdo temático, estilo e construção.

Nessa perspectiva, o gênero é historicamente situado, extremamente heterogêneo do ponto de vista da estrutura composicional, mas flexível, com uma expressividade típica, que revela a relação emotivo-valorativa do locutor com o objeto do discurso. Por outro lado, o gênero pode conter ou mimetizar outros, e misturar-se com outros, ser modificado na recepção, sobretudo ao longo da história. Se alguns gêneros podem tender para a homogeneidade, como por exemplo, um relato composto de indicações de ações sucessivas, outros são tendencialmente heterogêneos, comportando explicações, narrativas, comentários, discurso reportado, entre outros, como mostra François (2009). No caso do discurso acadêmico, a tendência é considerálo como predominantemente explicativo ou argumentativo (POLLET, 1997), no entanto, como todo gênero, ele é heterogêneo do ponto de vista textual, com variações 
incessantes nos movimentos dialógicos (interação constante com os discursos alheios) e discursivos (modos particulares de encadeamento intra e inter enunciados). ${ }^{6} \mathrm{Na}$ análise, os movimentos serão observados não do ponto de vista formal, como em alguns estudos sobre as sequências que compõem o texto (ADAM, 1992; 1997), mas na perspectiva de François (2009) para quem é necessário seguir os movimentos do texto numa perspectiva discursiva.

As noções brevemente apresentadas acima estão articuladas e não explicitam um quadro teórico "completo" ou uma "grade de análise" aplicável a todo texto. Elas vão funcionar como "lentes" para o exame dos artigos selecionados.

\section{Leituras do corpus}

O corpus é bastante longo para uma análise detalhada de cada texto. Por isso, o foco será a relação com o discurso alheio e alguns movimentos a ela ligados.

O primeiro artigo, Ditadura, anistia e reconciliação, aparenta homogeneidade enunciativa, numa campo de atividade em que a heterovocalidade é bastante marcada, o que me levou à leitura do segundo texto do mesmo autor para verificar se tratava-se do seu estilo ou se devia-se ao fato de o primeiro ter sido apresentado como Aula Inaugural do Programa de Pós-Graduação em História, Política e Bens Culturais do CPDOC/FGV. A questão era saber se a homogeneidade seria decorrente do gênero aula, e mais especificamente, da "conversa”, forma como Aarão Reis (2010) se refere à aula inaugural.

Depois de fazer uma reflexão sobre as relações entre Memória e História, o autor discute "questões e pontos de vista polêmicos" sobre a Lei da Anistia e os silêncios que ela estabeleceu sobre a tortura e os torturadores, sobre o apoio da sociedade à ditadura e sobre os projetos revolucionários de esquerda.

É importante destacar que Aarão Reis (2010) defende um ponto de vista - a

\footnotetext{
${ }^{6}$ Os textos são construídos e interpretados como movimentos e não como sucessão de frases (FRANÇOIS, 2009).
} 
necessidade da revisão da lei - porque considera que o debate poderia ajudar a sociedade brasileira a compreender melhor o período ditatorial e a tortura como política de Estado; a julgar os torturadores; e levar à abertura dos arquivos dos serviços secretos das Forças Armadas. Ao longo do texto, o autor narra acontecimentos que vão servir de argumentos para seu ponto de vista. Como ocorre em outros gêneros, a narrativa não é uma forma composicional pura.

O texto alterna movimentos argumentativos, narrativos e comentários sobre o narrado, com uso da primeira pessoa. Diferentemente de uma visão como a de Benveniste (1966) que caracteriza a narrativa histórica pelo uso da $3^{\underline{a}}$ pessoa, dos tempos verbais do pretérito, e pela ausência de modalização, este artigo não narra apenas "fatos históricos”. Como explica o próprio Aarão Reis (2010), referindo-se à história:

(1) perdeu-se há muito a ambição de objetividade em que os antigos acreditavam. Cada historiador tem um ângulo de análise, pressupostos e premissas, abordagens específicas, objetivos a alcançar, o que me tem levado, cada vez mais, a conceber a história como uma disciplina, uma arte, mais do que propriamente uma ciência...uma discussão que nos levaria longe, em outras direções (AARÃO REIS, 2010, p. 172).

O historiador faz pouquíssimas citações, entretanto, ele anuncia que trabalha com referências publicadas, livros e artigos, sem repeti-las, pelo fato de sempre efetuar “ajustes e redefinições, retoques, suscitados por sucessivos debates e pela reflexão sempre cambiante sob o influxo das circunstâncias e das polêmicas do tempo em que se vive” (AARÃO REIS, 2010, p. 172). Sabemos, então, de antemão que se trata de um texto sem marcas visíveis de interação com o discurso do outro. Contudo, há formas e graus de alteridade nessa aparente homogeneidade. Vejamos alguns exemplos.

Quando defende seu ponto de vista acerca do silêncio sobre a tortura e os torturadores, ressaltando que não foi unânime e que houve vozes isoladas, Aarão Reis introduz um exemplo:

o livro de Fernando Gabeira, publicado em 1979, desempenharia aí importante papel. Bem escrito, com tratamento irônico de temas candentes, ofereceu uma interpretação bem-humorada e conciliatória da ditadura e das lutas empreendidas contra ela (AARÃO REIS, 2010, p. 183). 
Não se trata de citação de fragmentos, nem de referência a um autor para sustentar seu ponto de vista. Temos a indicação de uma obra em um breve comentário irônico, para ilustrar o seu ponto de vista, embora seja uma forma de introdução do outro no texto relativamente homogêneo.

O pesquisador também faz referências em notas de rodapé à dissertação de mestrado, teses, ensaios sobre os temas discutidos, precedidas ou acompanhadas de comentários, como nos exemplos a seguir:

(2) Infelizmente, só há um trabalho acadêmico a respeito, sintomaticamente não publicado, o de Aline Alves Presot, 2004. (AARÃO REIS, 2010: 183).

(3) Cf. Janaína Martins Cordeiro, que, em pesquisa em curso para sua tese de doutoramento a respeito das comemorações do Sesquicentenário da Independência, realizadas em 1972, encontrou, em pesquisas do IBOPE (São Paulo e interior), índices de aprovação de $84 \%$ ao general. (AARÃO REIS, 2010: 13).

(4) Cf. Lucia Grinberg, 2009. (AARÃO REIS, 2010: 13)

Das vinte notas de rodapé, dez são referências de obras, com ou sem comentários apreciativos que servem para ilustrar o ponto de vista do autor ${ }^{7}$. Embora as vozes não sejam mostradas na composição do texto, ele é constitutivamente dialógico, tendo em vista que o ponto de vista - necessidade de revisão da Lei da Anistia de 1979, que configurou um pacto da sociedade ${ }^{8}$ - pressupõe outro ponto de vista, ou um contradiscurso, ao qual ele se opõe.

No artigo, As revoluções russas e a emergência do socialismo autoritário, escrito na ocasião do centenário da revolução russa, Aarão Reis (2017) questiona os lugarescomuns relativos aos acontecimentos ligados à insurreição de Outubro, em particular à atuação do partido bolchevique, ou às ideias e propostas de Vladímir Lenin. Defende o ponto de vista segundo o qual esses lugares comuns são um equívoco, uma reiteração de uma dupla tradição: a da historiografia soviética e a da historiografia liberal, que

\footnotetext{
$7 \mathrm{O}$ texto tem treze páginas e um total de 9084 palavras.

${ }^{8}$ Os itálicos são do autor.
} 
marcaram com suas interpretações e simplificações, o período da guerra fria. E propõe um outro caminho, baseado em seus movimentos interpretativos.

O texto de treze páginas apresenta cronologicamente o ciclo de revoluções ocorridas entre 1905 e 1921, mas parte de um ponto de vista: a Revolução de Outubro e seus desdobramentos só se tornam inteligíveis neste contexto mais amplo. Aarão Reis (2017, p. 67) alterna ponto de vista e narrativa, ou narrativa e comentário, como no exemplo a seguir: "1905. A primeira revolução do ciclo ocorreu entre janeiro e dezembro de 1905 (TROTSKY, 1975). [...] Três aspectos mais relevantes poderiam ser considerados.”

Diferentemente do anterior, esse artigo traz numerosas referências a outros autores no corpo do texto, e apenas uma nota de rodapé. Do ponto de vista da materialidade linguística, a escrita parece impessoal e homogênea, embora seja um texto em $1^{\underline{a}}$ pessoa, cuja marca só aparece no final do artigo: "Entretanto, no contexto das guerras civis, como esperamos ter demonstrado, ocorreu uma revolução na revolução.” (AARÃO REIS, 2017, p. 74). Isto mostra que não é a presença de tais marcas que torna o texto objetivo ou subjetivo, "científico" ou não.

O pesquisador faz uso frequente de aspas em palavras ou expressões, o que é uma marca de heterogeneidade enunciativa (AUTHIER-REVUZ, 2004)9. Há cinco ocorrências de citação de fragmentos, seguida da referência, como nos exemplos a seguir.

(5) A Rússia tornara-se a sociedade mais livre do mundo de então, um lugar onde "todos queriam mandar e ninguém queria obedecer" (Sukhanov, 1962). (AARÃO REIS, 2010, p. 69).

(6) Foi por isso que a vitória de outubro foi "mais fácil do que levantar uma pluma”, como reconheceu V. Lenin. (AARÃO REIS, 2010, p. 7o).

(7) Condescendente e ironicamente, K. Kautsky batizou a experiência de "socialismo de quartel" (Kautsky; Lenin, 1979). Outros, como os anarquistas, a classificaram como "capitalismo de Estado" (Volin, 1975). Finalmente, entre os próprios socialistas russos, mais tarde, apareceria a crítica de um "socialismo degenerado” (Trotsky, 1978a; Deutscher, 1966). (AARÃO REIS, 2010, p. 74).

(8) Na sua famosa polêmica com K. Kautsky, (Lênin) defenderia a organização soviética como "mil vezes mais democrática" do que o mais democrático parlamento europeu (Kautsky; Lenin, 1979). (AARÃO REIS, 2010, p. 74).

\footnotetext{
${ }_{9}$ Para analisar as vozes no discurso, retomamos algumas categorias elaboradas por Authier-Revuz, que faz uma descrição minuciosa das formas de "representação do discurso outro" em sua obra, enquanto Volóchinov (2017) e Bakhtin (2015; 1997) se interessam particularmente pelas formas não marcadas de discurso alheio.
} 
Essas formas são classificadas por Authier-Revuz (2015) como modalidade autonímica de empréstimo. Nesses casos, se fala de um objeto qualquer a partir de um outro discurso cuja imagem passa pela exposição das palavras. Esse setor da modalização autonímica de empréstimo faz parte do campo global da modalidade autonímica, ou seja, quando há uso e menção das palavras.

O que mais chama atenção no artigo é que o autor não utiliza formas de citações diretas ou indiretas, como veremos nos artigos de Capelato e Carvalho, mas faz uso de um número elevado de referências a outros autores e obras (setenta e seis ocorrências) todas no formato dos exemplos (9) e (10):

(9) De outro lado, irromperam, como em 1905, em toda parte, no campo e na cidade, entre os russos e os não russos, organizações políticas de todos os tipos, autônomas, e que só obedeciam a diretivas que considerassem corresponder a suas aspirações e interesses - uma situação de múltiplos poderes (Ferro, 1967; Rabinovitch, 1968, 2004; Raleigh, 1986 e 2001; Reis, 2004; Suny, 1972), muito diferente de certo lugar-comum, enunciado pioneiramente por L.Trotsky $(1978 \mathrm{a} / \mathrm{b})$, que descreveu a sociedade polarizada por um duplo poder (AARÃO REIS, 2010, p. 69).

(10) Com o desaparecimento do "centro" autocrático, que, de modo algum, pode ser assemelhado aos Estados existentes na Europa, eis que aspirava tudo dominar, e ignorava a noção de cidadania, inibindo ou reprimindo a vigência de qualquer instituição intermediária (Ingerflom, 2015), apareceu uma situação nova, inédita na história russa, de dispersão e disseminação horizontal das referências de poder (Ferro, 2011; Reis, 2017). Como se, dos palácios, o poder tivesse migrado para as ruas. (AARÃO REIS, 2010, p. 69)

Neste tipo de introdução do outro, em que não há marcas delimitando as vozes, ou melhor, com a completa fusão das vozes, discurso próprio e discurso alheio se misturam formando um todo bivocal. Convém ressaltar que essa bivocalidade é distinta daquela do romance que é orientada para a imagem da linguagem (BAKHTIN, 2015), e do relato autobiográfico (VALOIS \& CUNHA, 2012) ${ }^{10}$. A bivocalidade nos gêneros

\footnotetext{
10 Para Bakhtin (1997, p. 273), "as palavras do outro, introduzidas na nossa fala, são revestidas inevitavelmente de algo novo, da nossa compreensão e da nossa avaliação, isto é, tornam-se bivocais. [...] O nosso discurso da vida prática está cheio de palavras de outros. Com algumas delas fundimos inteiramente a nossa voz, esquecendo-nos de quem são; com outras, reforçamos as nossas próprias palavras, aceitando aquelas como autorizadas para nós; por último, revestimos terceiras das nossas próprias intenções, que são estranhas e hostis a elas".
} 
acadêmicos seria aquela que se revela por meio da referência posterior a um autor ou mais autores ou a uma obra no final do enunciado.

É possível então dizer que essa forma de presença da alteridade - fruto do processo de assimilação dos discursos alheios - desenha um estilo, o de um teórico, com voz própria, que escreve com suas próprias palavras, sem citações com função de argumento de autoridade ou outra.

O trabalho de M. H. Capelato, História do Brasil e revisões historiográficas, objetiva analisar o significado de revisões historiográficas relacionadas à história do Brasil, para mostrar como são estabelecidas revisões a partir da construção e reconstrução de memórias históricas, por ocasião das comemorações de datas históricas e através de usos políticos do passado motivados por interesses político-partidários. A historiadora postula que as revisões são fabricadas a partir de interesses alheios ao campo do conhecimento histórico.

É um texto de dezesseis páginas, em $1^{\underline{a}}$ pessoa, que começa com uma definição de história, no início do 1ํo parágrafo, citando dois historiadores célebres:

(11) O historiador Marc Bloch definiu a história como "ciência dos homens no tempo" e sublinhou como características implícitas dessa ciência o seu caráter humano e as relações entre passado e presente. Com relação a este último aspecto, chamou a atenção para a importância de se compreender o "presente pelo passado" e o "passado pelo presente", nunca pelas vias de um trajeto linear, mas levando em conta as rupturas e continuidades. Além disso, salienta que a visão de um mesmo passado se modifica de acordo com as mudanças de longa, média e curta duração (LE GOFF, 1990, p. 23-24). (CAPELATO, 2016, p. 21).

A partir do 2º parágrafo, o texto alterna narração das "revisões históricas: décadas de 1970-1980" e explicações. A autora faz referências a outros autores, sem citá-los, e faz uso do discurso indireto sem indicação da autoria (12 e 13):

(12) [...] As análises dos filósofos Claude Lefort, Cornelius Castoriadis e historiadores como Bronislaw Baczko, René Girard e Peter Burke inspiraram pesquisas sobre representações políticas e imaginários sociais, campo novo na historiografia brasileira (CAPELATO, 2016, p. 26).

(13) Os historiadores que abriram caminho para a aceitação dessa nova corrente historiográfica comentam que houve forte recusa com relação à chamada história imediata ou história do tempo presente, sob alegação de falta 
de recuo em relação ao passado e aproximação com o periodismo (CAPELATO, 2016, p. 26).

Como se vê, Capelato (2016) apresenta, na forma de relato, pesquisas historiográficas, francesas e brasileiras de forma genérica, sem referências a autores nesses fragmentos e em vários momentos do texto.

A partir da metade do artigo, do item V, mais precisamente, Centenário da descoberta do Brasil: revisões historiográficas, festas cívicas e manifestações sociais, a pesquisadora relata esses acontecimentos, alternando referências (exemplo 14) e citações em formas diversas (exemplos 15 a 17):

(14) As festas cívicas também dão ensejo à construção e reconstrução de novas formas de representação da história que incluem revisão de memórias coletivas, invenção e reinvenção de identidades nacionais utilizadas como instrumento eficaz para exacerbação de sentimentos patrióticos, sobretudo num contexto de conflitos sociais e luta política intensa (CANDINA, 2002). (CAPELATO, 2016, p. 28).

(15) O literato Machado de Assis fez um comentário irônico, mas muito pertinente, a um amigo que procurava explicar o significado do acontecimento "Independência do Brasil". Segundo a versão do amigo sobre o episódio: "Houve uma resolução do Príncipe Dom Pedro sobre independência e o mais; mas não foi positivamente um grito, nem elle se deu nas margens do celebre ribeiro. Lá se vão páginas dos historiadores". (SANDES, 200o, s. p.). (CAPELATO, 2016, p. 29). O literato comenta essa explicação nos seguintes termos:

[...] durante cinquenta e quatro anos ouvi repetir uma cousa que o amigo diz não ter existido. [...] Minha opinião é que a lenda é melhor do que a historia authentica. A lenda resume todo o fato da independência nacional, ao passo que a versão exata o reduz a uma cousa vaga e anonyma. Tenha paciência o meu ilustrado amigo; é mais summario, mais bonito e mais genérico (SANDES, 2000, p. 09-21, contracapa). (CAPELATO, 2016, p. 29).

(16) [...] A propósito da presença da parada militar no rito comemorativo, cabe lembrar que o antropólogo Roberto DaMatta (1986) referiu-se a esse tipo de comemoração como "festas da ordem". (CAPELATO, 2016, p. 29).

(17) O historiador Noé Freire Sandes (200o) analisou o tema procurando mostrar como foi feita, naquele momento, a releitura do passado acompanhada de ressignificação de imagens e símbolos. Mostra que não só atores políticos, mas também literatos, dramaturgos, pintores, historiadores foram responsáveis pelo redesenho da nacionalidade e dos rumos de seu futuro. Analisou o significado do "Grito do Ipiranga", gesto de emancipação consagrado através da figura do Príncipe, construída através dos pincéis de Pedro Américo no final do século XIX. (CAPELATO, 2016, p. 29). 
No exemplo 15, há três camadas enunciativas visíveis: a voz da autora, do amigo de Machado de Assis e de Sandes, o que ilustra bem o que diz Bakhtin (2003), sobre o texto nas ciências humanas (“textos sobre textos”) e Latour e Fabri (1977) no artigo sobre a retórica da ciência. Nos fragmentos 16 e 17, há variantes do esquema de discurso indireto, com condensação e narrativização do conteúdo, ou seja, com relatos dos atos de fala e não com paráfrases do discurso fonte.

O artigo alterna narração, explicação e posicionamentos avaliativos. Na parte do texto, em que apresenta as revisões históricas, Capelato (2016) traz outras vozes, em vinte e quatro (24) referências, inserções de vozes de teóricos na maioria das ocorrências. Ao longo do texto, a historiadora faz uso de uma pluralidade de formas de relação aos dizeres alheios: referência no discurso próprio a um autor no final de um parágrafo, como faz Aarão Reis Filho (2017); discurso reportado sem indicação da fonte, citação direta, citação indireta (com uso da expressão segundo X), formas de modalidade autonímica de empréstimo com indicação do autor das palavras citadas. Trata-se, portanto, de um estilo em que a heterovocalidade é frequente e visível, sendo, portanto, constitutiva da composição do texto e do estilo da autora.

O artigo do célebre historiador, citado inclusive por Capelato (2017), José Murilo de Carvalho, República, democracia e federalismo. Brasil, 1870-1891, escrito a convite da revista, tem dezessete páginas. De acordo com o resumo, ele tenta explicar a mudança ocorrida com a transformação dos radicais liberais em republicanos, a partir do Manifesto Republicano de 1870, que provocou um retrocesso conservador e suspendeu o programa de reformas sociais e políticas, proposto pelos radicais durante a década de 1860. Para tanto, o historiador analisa a formação do campo conceitual republicano entre 1870 e a promulgação da Constituição de 1891.

É um texto com propósito explicativo, conforme as palavras do autor, em $1^{\underline{a}}$ pessoa, mas a forma composicional predominante é narrativa, uma vez que analisa os manifestos do Partido Republicano, no âmbito nacional e local (de São Paulo, Pernambuco e Pará), nos Anais da Constituinte Republicana e nas obras dos principais teóricos do Partido no período da propaganda. Desse modo, traz o contexto, as discussões, a visão dos intelectuais da época, ou seja, vozes do passado, do século XIX, 
mais precisamente, e de estudiosos que precederam o historiador. A argumentação se dá por meio da narrativa, como nos artigos anteriores.

O texto é bastante denso, com análise de muitos documentos, de discursos de muitos autores, examinando o "leque temático do debate republicano" (CARVALHO, 2011, p. 142); "as ideias republicanas, com ênfase nos conceitos de república, democracia e federalismo e nas relações que mantinham" (CARVALHO, 2011, p. 145); e a mudança de paradigma ocorrida.

O historiador começa com a retomada em discurso indireto de um trabalho do próprio autor para depois fazer o anúncio do foco do artigo:

(18) Em trabalho anterior, argumentei que a transformação do radicalismo liberal em republicanismo representou um retrocesso ou, no mínimo, uma parada na luta pelas reformas políticas e sociais. $\mathrm{O}$ fato se deveu à concentração do debate, operada após o Manifesto Republicano de 1870, em torno da forma de governo, monarquia ou república, com prejuízo de outros temas de igual, ou maior, relevâncial. Trato agora de examinar com maior profundidade o campo do debate republicano em sua amplitude temática e conteúdo conceitual.

1 CARVALHO, José Murilo de. Radicalismo e republicanismo. In: CARVALHO, José Murilo de e NEVES, Lúcia Maria Bastos Pereira das. (orgs.) Repensando o Brasil do Oitocentos: cidadania, política e liberdade. Rio de Janeiro: Civilização Brasileira, 2009, p.19-48. (CARVALHO, 2011, p. 142)

Ao longo da análise, Carvalho retoma, no texto e nas notas de rodapé, trabalhos de numerosos escritores, em formas diversas: citações diretas, discurso indireto e discurso indireto com fragmentos do discurso do outro mostrados, modalidades autonímicas de empréstimo (“a democracia brasileira”) e faz uso frequente de expressões como "segundo", seguidas das palavras do texto, ou seja, ele diz de acordo com o outro, e mostra parte do dizer, das palavras do outro (fragmento 19):

(19) Segundo o documento, se "a democracia brasileira" colocasse tal dispositivo em seu programa, "alienaria de si a maior parte das adesões que tem e as simpatias que espera atrair". Candidamente, confessava-se que o apoio à abolição reduziria as adesões ao partido5.

5 Para uma exposição detalhada da posição do Partido Republicano Paulista, ver SANTOS, José Maria dos. Os republicanos paulistas e a abolição. São Paulo: Martins Fontes, 1942 (CARVALHO, 2011, p. 142). 
$\mathrm{O}$ artigo tem quarenta notas de rodapé nas quais faz referências aos autores que escreveram sobre o tema e que ele cita ou indica para os leitores. Na realidade, as notas de rodapé do historiador mereceriam um outro estudo. Há notas sem comentários, como a do exemplo 18, notas com comentários avaliativos, como a nota 5 do exemplo 19 sobre o Partido Republicano, notas com comentário avaliativo de obras, como a do exemplo 20:

(20) É certo, no entanto, que só em São Paulo se formou um verdadeiro partido, com organização, disciplina e capacidade de competição eleitoral”2.

2 A melhor história do Partido Republicano ainda á a de BOEHRER, George C.A. Da Monarquia à República: História do Partido Republicano do Brasil (1870-1889). Rio de Janeiro: Ministério da Educação e Cultura, 1954 (CARVALHO, 2011, p. 142).

As notas revelam uma grande cultura do autor na sua área de conhecimento. Ao todo, Carvalho menciona quarenta autores, algumas vezes com citação de fragmentos, e cita quarenta e três obras. Apenas três autores aparecem tanto no texto como nas notas. Esses movimentos de introdução da heterovocalidade, seus modos de dizer específicos, constroem um estilo do autor.

\section{Considerações finais}

Ao final desse percurso, convém apresentar o que esses artigos da área de História têm em comum e as diferenças. Em comum, pode-se apontar o uso de alguns esquemas de retomada dos dizeres alheios: modalidade autonímica de empréstimo, citações diretas, discurso indireto nas formas canônicas, seguidas ou não de citação de fragmentos, discurso indireto, incluindo a forma narrativizada, e por meio das expressões "segundo X", "para X". Capelato (2016) e Carvalho (2011) fazem uso desses esquemas de retomada do discurso alheio, enquanto Aarão Reis (2017) bem como Carvalho (2011) fazem uso de referência a numeroso autores e obras nas notas de rodapé. 
Como foi visto, a escrita de Aarão Reis (2010 e 2017) chama atenção pela aparente "homogeneidade enunciativa", principalmente no primeiro artigo, numa esfera em que a heterovocalidade é bastante marcada, em razão das regras explicitamente definidas dos modos de citar. No primeiro texto, aparecem referências em oito notas de rodapé, uma das quais traz sete e outra cinco autores, ou seja, são mencionados dezoito autores. Ao longo do texto, o historiador usa expressões entre aspas para se distanciar de algumas formulações, mas o texto é constitutivamente dialógico na medida em que defende um ponto de vista que é necessariamente construído em relação a outro(s) e mais ainda por ser de caráter polêmico. É possível sugerir que a heterogeneidade não marcada é decorrente do gênero conferência, publicada na forma de artigo. No segundo artigo, o outro se faz presente por meio de numerosas referências inseridas no texto a autores e obras, que estão na base do pensamento do historiador.

O artigo de Capelato (2016) traz uma primeira parte mais homogênea, na voz da autora, e na segunda, numerosas citações e referências. O texto traz uma única nota de rodapé com indicação da fonte de duas citações de internautas.

O texto de Carvalho (2011) é complexo, aparentemente homogêneo no início, do ponto de vista da alteridade, mas as quarenta notas de rodapé trazem uma pluralidade de vozes e de modos de introduzi-las: sem comentários, com comentários avaliativos e com indicações de leituras.

Vemos, portanto, que os textos do campo da História são constitutivamente dialógicos, heterovocais com vozes marcadas e identificáveis na linearidade, vozes e pontos de vista presentes, amalgamados ao discurso do autor. Do ponto de vista teórico, merece destaque em primeiro lugar a diversidade de estilos dos artigos acadêmicos. Contudo, o resultado mais interessante é que um dos modos particulares desse gênero é a referência a outros autores ao final do enunciado, no corpo do texto ou nas notas de rodapé, impossibilitando a identificação do discurso próprio e do discurso alheio. Nesses casos, é possível dizer que o artigo acadêmico é heterovocal, mas contém momentos em que é bivocal, em razão da fusão de vozes quando se apresenta apenas a referência. Nesses casos, também não é possível distinguir o ponto de vista dos historiadores e dos autores mencionados, uma vez que o primeiro resulta do trabalho 
interpretativo dos últimos. Esses estilos de interação remetem à diversidade de modos de conceber a escrita desse gênero.

Por fim, os artigos mostram ainda a heterogeneidade da forma composicional, levando a questões sobre a escrita acadêmica e sobre a caracterização do texto acadêmico como explicativo. Na realidade, nos artigos acadêmicos da área de História, o autor parte de um ponto de vista e desenvolve a argumentação alternando explicações, narrativas e comentários avaliativos.

Esse estudo empírico pode fornecer subsídios para a reflexão sobre a noção de ciência e de cientificidade na área de ciências humanas, tendo em vista a impossibilidade de se enunciar sem se posicionar. Pode, por fim, contribuir para a formação da escrita acadêmica e profissional em contextos de formação profissional e para o domínio da escrita de uma forma geral.

\section{Referências}

AARÃO REIS, Daniel. 2017. As revoluções russas e a emergência do socialismo autoritário. Estudos Avançados, São Paulo, vol. 31 (91), p. 67-79.

AARÃO REIS, Daniel. 2010. Ditadura, anistia e reconciliação. Estudos Históricos, Rio de Janeiro, vol. 23, no 45, p. 171-186.

ADAM, Jean-Michel. Genres, textes, discours: pour une reconception linguistique du concept de genre. In: Revue belge de philologie et d'histoire, tome 75, fasc. 3. Langues et littératures modernes - Moderne taal- en letterkunde. p. 665-681, 1997.

. Les textes: types et prototypes. Paris, Nathan, 1992.

AUTHIER-REVUZ, Jacqueline. La représentation du discours autre. Principes pour une description. Paris, De Gruyter, 2020.

A representação do discurso outro: um campo multiplamente heterogêneo. Trad. Heber O. Costa e Silva e Dóris de Arruda C. da Cunha. Investigações, Linguística e Teoria da literatura. Recife, Vol. 28, Número especial, p. 1-39, 2015. 
Heterogeneidade mostrada e heterogeneidade constitutiva, elementos para uma abordagem do outro no discurso. In: Entre a transparência e a opacidade: um estudo enunciativo do sentido. Porto Alegre: EDIPUCRS, p. 11-8o, 2004.

BAKHTIN, Mikhail. Os gêneros do discurso. Organização, tradução, posfácio e notas de Paulo Bezerra. São Paulo, Editora 34, 2016.

. Teoria do romance I. A estilística. Trad. Paulo Bezerra. São Paulo: Editora 34, 2015 .

. Para uma filosofia do ato responsável. Trad. Valdemir Miotelo e Carlos Alberto Faraco. São Carlos: Pedro e João Editores, 2010.

Estética da criação verbal. Trad. Paulo Bezerra. 4 ed. São Paulo: Martins Fontes, 2003.

. Problemas da poética de Dostoïevski. 2 ed. Trad. Paulo Bezerra. Rio de Janeiro: Forense Universitária, 1997.

BENVENISTE, Emile. Problèmes de linguistique générale. Paris: Gallimard, 1996.

CAPELATO, Maria Helena. História do Brasil e revisões historiográficas. Anos 9o, Porto Alegre, vol. 23, n. 43, p. 21-37. 2016

CARVALHO, J. M. República, democracia e federalismo. Brasil, 1870-1891. VARIA HISTÓRIA, Belo Horizonte, vol. 27, no 45: p.141-157, jan/jun 2011.

CUNHA, Dóris de Arruda Carneiro da. Discurso outro e discurso próprio em textos acadêmicos. In: Ana Zandwais; Luciano Vidon (org.). A pesquisa sob o enfoque dos estudos do Círculo de Bakhtin. Vitória: EDUFES, 2019.

. Formes et degrés d'orientation dialogique, genre et point de vue. In: BrancaRosoff, S. et al. (éds) L'hétérogénéité à l'œuvre dans la langue et le discours. Hommage à Jacqueline Authier-Revuz. Limoges: Lambert-Lucas, 2012. p. 289-301.

. Formas de presença do outro na circulação dos discursos. Bakhtiniana, São Paulo, v. 1, n. 5, 2011.

. Do discurso citado à circulação dos discursos: a reformulação bakhtiniana de uma noção gramatical. Matraga, Rio de Janeiro, n. 22, p. 129-144, 2008.

Discours rapporté et circulation de la parole. Leuven/Louvain-la-Neuve: Peeters/Louvain-la-Neuve, 1992, 231 p. 
FARACO, Carlos Alberto. Bakhtin e filosofia. Bakhtiniana, São Paulo, Vol. 12 (2), p. 45$56,2017$.

A ideologia no/do Círculo de Bakhtin. In : Luciane de Paula ; Grenissa Stafuzza (Org.). Círculo de Bakhtin: pensamento interacional. Série Bakhtin - Inclassificável, vol. 3. Campinas: Mercado de Letras, p. 167-182, 2013.

FRANÇOIS, Frédéric. Introduction. Quelques points de vue sur point de vue. In: Marie Carcassonne et al. Points de vue sur point de vue. Un essai de réflexion collective. Limoges: Lambert-Lucas, p. 7-75, 2015.

. Communautés et divergences dans l'interprétation. Introduction langagière à un projet de «psychologie concrète». Limoges: Lambert-Lucas, 2014.

Essais sur quelques figures de l'orientation. Hétérogénéité, mouvements et styles. Limoges: Lambert-Lucas, 2009.

GINGRAS, Yves. Sociologie des sciences. Paris, PUF, 2013.

LATOUR, Bruno; FABRI, Paolo. La rhétorique de la Science. Actes de la recherche en sciences sociales. Paris, Vol. 13, N. 1, p. 81-95, 1977.

LÖWY, Michael. As aventuras de Karl Marx contra o Barão de Münchhausen. Marxismo e positivismo na sociologia do conhecimento. 7. ed. São Paulo: Cortez, 2000.

POLLET Marie-Christine. Discours universitaires ou genre académique : l'explicatif comme zone de (dis)continuité. In: Revue belge de philologie et d'histoire, Bruxelas, tome 75, fasc. 3, p. 771-787, 1997.

VALOIS, Michelle; CUNHA, Dóris de Arruda Carneiro da. La bivocalité dans un récit autobiographique. Le discours et la langue. Bruxelas, Vol. 2, p. 37- 48, 2012.

VOLÓCHINOV, Valentin. (Círculo de Bakhtin). Marxismo e filosofia da linguagem. Problemas fundamentais do método sociológico na ciência da linguagem. Tradução Sheila Griollo e Ekaterina Vólkova Américo. São Paulo: Editora 34, 2017.

Recebido em 31/o7/2020.

Aprovado em 01/10/2020. 